\title{
Spatial distribution of earthquakes off the east coast of the Kanto region along the Japan Trench deduced from ocean bottom seismographic observations and their relations with the aftershock sequence of the 2011 off the Pacific coast of Tohoku Earthquake
}

\author{
Tomoaki Yamada ${ }^{1}$, Kazuo Nakahigashi ${ }^{1}$, Asako Kuwano ${ }^{1}$, Kimihiro Mochizuki ${ }^{1}$, Shin'ichi Sakai ${ }^{1}$, \\ Masanao Shinohara ${ }^{1}$, Ryota Hino ${ }^{2}$, Yoshio Murai ${ }^{3}$, Tetsuo Takanami ${ }^{3}$, and Toshihiko Kanazawa ${ }^{1}$ \\ ${ }^{1}$ Earthquake Research Institute, University of Tokyo, Tokyo 113-0032, Japan \\ ${ }^{2}$ Graduate School of Science, Tohoku University, Sendai 980-8578, Japan \\ ${ }^{3}$ Institute of Seismology and Volcanology, Hokkaido University, Sapporo 060-0810, Japan
}

(Received April 22, 2011; Revised June 22, 2011; Accepted June 23, 2011; Online published September 27, 2011)

\begin{abstract}
The 2011 Tohoku earthquake hit the forearc region of the Japan Trench on March 11, 2011. The rupture zone seemed to reach off the coast of the Kanto region. We had conducted ocean bottom seismographic observations off the coast of the Kanto in 2008 and estimated 851 hypocenter locations around the south part of the 2011 off the Pacific coast of Tohoku Earthquake by using over 50 ocean bottom seismometers (OBSs) and routine data jointly. The hypocenters distributed some clusters, and we found a few seismic gaps at the boundary zones of the clusters. The most remarkable seismic gap was positioned at the edge of intervened Philippine Sea plate (PHS) between the North American plate (NA) and Pacific plate (PAC). We compare the epicenter distributions with the 2011 aftershock distribution determined by routine data. The aftershocks are segmented spatially and there are some seismic gaps among the segments. The remarkable low places are consistent with the boundary zones of each cluster we estimated from the 2008 data. We infer that those regions have strong heterogeneity resulting from strong deformations caused by various subduction processes, such as intervening PHS between NA and PAC, seamount chains and changes in physical properties.
\end{abstract}

Key words: Seismic gap, Philippine Sea plate, Pacific plate, subduction, Japan Trench, the 2011 off the Pacific coast of Tohoku Earthquake.

\section{Introduction}

The 2011 off the Pacific coast of Tohoku Earthquake whose magnitude $M_{\mathrm{j}}$ was 9.0 , determined by the Japan Meteorological Agency (JMA), occurred near the east coast of Honshu, Japan on March 11, 2011 in the subduction zone of the Pacific plate (PAC). The rupture spread away both north and south and a large aftershock $\left(M_{\mathrm{j}} 7.7\right)$ hit at the south end about 30 minutes after the mainshock. Seismic information such as the source mechanisms and the foci show that both events result from thrust faulting between the North American plate (NA) and the subducted PAC.

On the other hand, there is the Philippine Sea plate (PHS) adjacent to the region (Fig. 1(a)). Uchida et al. (2010) and others estimate the configuration of the PHS that contacts the PAC and these seem to define the rupture edge of the large earthquake (Shinohara et al., 2011). One of our interests is to understand the relationship of earthquake processes with plate interactions. Precise hypocenter distribution is the key to verifying the issue. Shinohara et al. (2011) have been observing the aftershocks just above the

Copyright (C) The Society of Geomagnetism and Earth, Planetary and Space Sciences (SGEPSS); The Seismological Society of Japan; The Volcanological Society of Japan; The Geodetic Society of Japan; The Japanese Society for Planetary Sciences; TERRAPUB.

doi:10.5047/eps.2011.06.045 rupture zones by using ocean bottom seismometers (OBSs) and these data and high dense land-based seismic data, such as Hi-net, should bring us the hypocenter distribution in fine detail. However, the results are unknown at present and the previous estimated hypocenter distribution before the temporal observation by Shinohara et al. (2011) has great ambiguity, since the region is located off shore and there are no routine seismic stations (e.g., Yamada et al., 2005; Hino et al., 2006; Shinohara et al., 2008).

In 2008, we conducted passive and active seismic experiments in which we used 55 OBSs (Fig. 1(b)). In this paper, we show the previous ocean bottom passive seismographic observations in 2008, their results, in particular hypocenter distribution and compare them with the recent massive seismic activity.

\section{Data and Method}

We combined data from 55 OBSs (Kanazawa et al., 2005; Shinohara et al., 2009) and 63 routine land-based seismic stations operated by the National Research Institute for Earth Science and Disaster Prevention (NIED), JMA, Tohoku University and the Earthquake Research Institute, University of Tokyo (Fig. 1(b)), picked $P$ and $S$ arrival times of 1100 earthquakes manually on a computer display (Urabe and Tsukada, 1991), located foci using a non- 


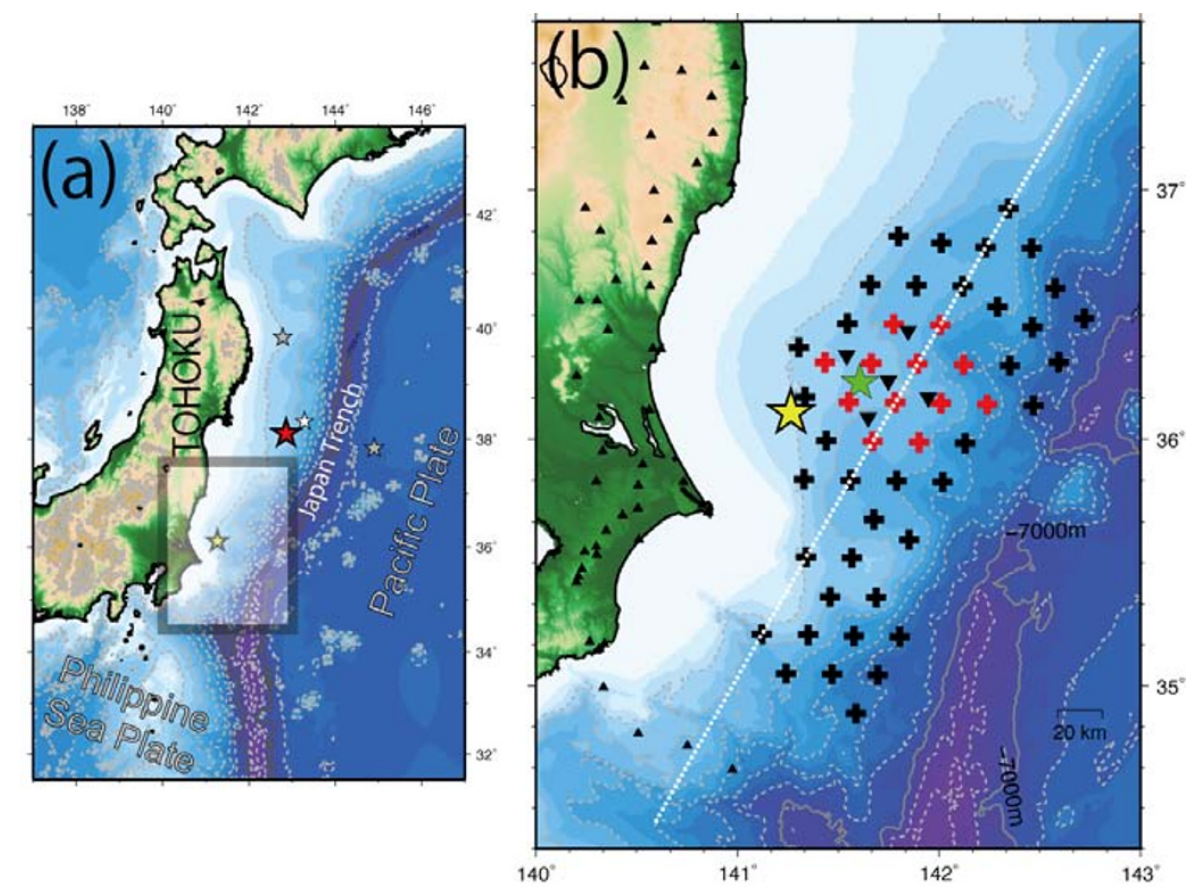

Fig. 1. (a) Location map of the 2011 off the Pacific of Tohoku Earthquake with bathymetry. The red star denotes epicenter of the $M_{\mathrm{j}} 9.0$ earthquake on March 11, 2011 and the yellow star represents the $M_{\mathrm{j}} 7.7$ aftershock about 30 minutes after the mainshock. Grey stars and a white star show the other $M_{\mathrm{j}} 7.4$ and $M_{\mathrm{j}} 7.5$ aftershocks on March 11, 2011 and the $M_{\mathrm{j}}, 7.3$ foreshock on March 9, 2011, 2 days before the mainshock. The rectangle depicts the area in (b). Broken lines and solid line denote contour intervals of $1 \mathrm{~km}$ water depth. Solid line corresponds to $7 \mathrm{~km}$ water depth. (b) The configuration of seismic stations used in this study. Yellow and green stars correspond to the $M_{\mathrm{j}} 7.7$ aftershock on May 11,2011 and the $M_{\mathrm{j}} 7.0$ earthquake on May 8, 2008, respectively. Red and black crosses denote 50 OBS stations of the experiment in 2008. We deployed the red ones on May 19, 2008 and the black ones were installed in June 25-27, 2008. The 50 OBSs were recovered in October, 2008. Inverted triangles are the other 5 OBSs of another experiment from October 13, 2007 to June 25, 2008. Triangles show the routine seismic stations we used. White dots represent blast points of TNT dynamite used in a refraction experiment (Nakahigashi et al.). Broken and solid lines denote contour intervals of $1 \mathrm{~km}$ and $7 \mathrm{~km}$ water depth, respectively.

linear global search algorithm (Lomax et al., 2009). We assumed $P$-wave velocity structure based on active seismic refraction surveys (Miura et al., 2003; Nakahigashi et al., in preparation) and $V_{p} / V_{s}$ ratio of 1.73 for travel time calculations. Lateral heterogeneity along the subducting direction was considered, although structural variation was neglected along the parallel trench direction. In general, structural undulation along the trench is less than along the subducting direction. In this study region, we have to pay attention to the contact zone between PAC and PHS. However, active source data show that the lateral velocity variation is smooth although the acoustic impedance contrast is clear at the boundary zone (Nakahigashi et al., in preparation). We applied time corrections for each station and each phase, to eliminating the effects of velocity uncertainly and heterogeneity, in particular just beneath the OBSs. These were derived from averaged differences between observed and calculated times in all hypocenters, and fixed after repeating the procedure five times.

\section{Results and Discussion}

Figure 2(a) shows the 851 hypocenters from May 19 to October 26, 2008 limited in and near the OBS network. The averaged standard errors are $0.24 \mathrm{~km}$ and $0.69 \mathrm{~km}$ in the horizontal and vertical directions, respectively. You can see some seismic gaps in regions $\mathrm{B}$ and $\mathrm{E}$ beneath the OBS network as well as some clusters in A, C and D.

Mechanism solutions by NIED (Fukuyama et al., 1998) with the focal depths deduced from this study (Fig. 2(b)) imply that low-angle thrust type earthquakes on the plate boundary have predominance in regions A-D. These are typical seismic patterns in subduction zones. In contrast, you can see another type of activity in region $\mathrm{E}$ near the coast. Vertical cross-sections (Fig. 2(c)) clearly show the discrepancy. Many hypocenters form a plane which represents the subducting PAC in regions A-D, although there are few events in the upper plate and the slab. Otherwise, the slab shape is unclear in region E, where PHS is estimated to be interposed. Focal depths are broad $(6-52 \mathrm{~km})$ and there are mechanism variations in the cluster near the coast and few events are in the forearc region except near the coast. The spatial differences of both hypocenter distribution patterns and mechanism solutions between regions A-D and region E seem to result from whether NA and PAC are in direct contact or PHS exists in between NA and PAC.

There is a clear seismic gap between regions D and E. The proposed PHS edge by repeating earthquakes (Uchida et al., 2010) and a seismic refraction survey (Nakahigashi et al., in preparation, Fig. 3) are located at the north-eastern end of the seismic gap and in the transition zone, respectively. In other words, the typical seismic patterns in regions A-D ended at the contact zone among NA, PAC and PHS or are separated by a deformation zone the interaction makes.

For the investigation of recent activities just after the $M_{\mathrm{j}} 9.0$ earthquake, we compared the hypocenter distribu- 

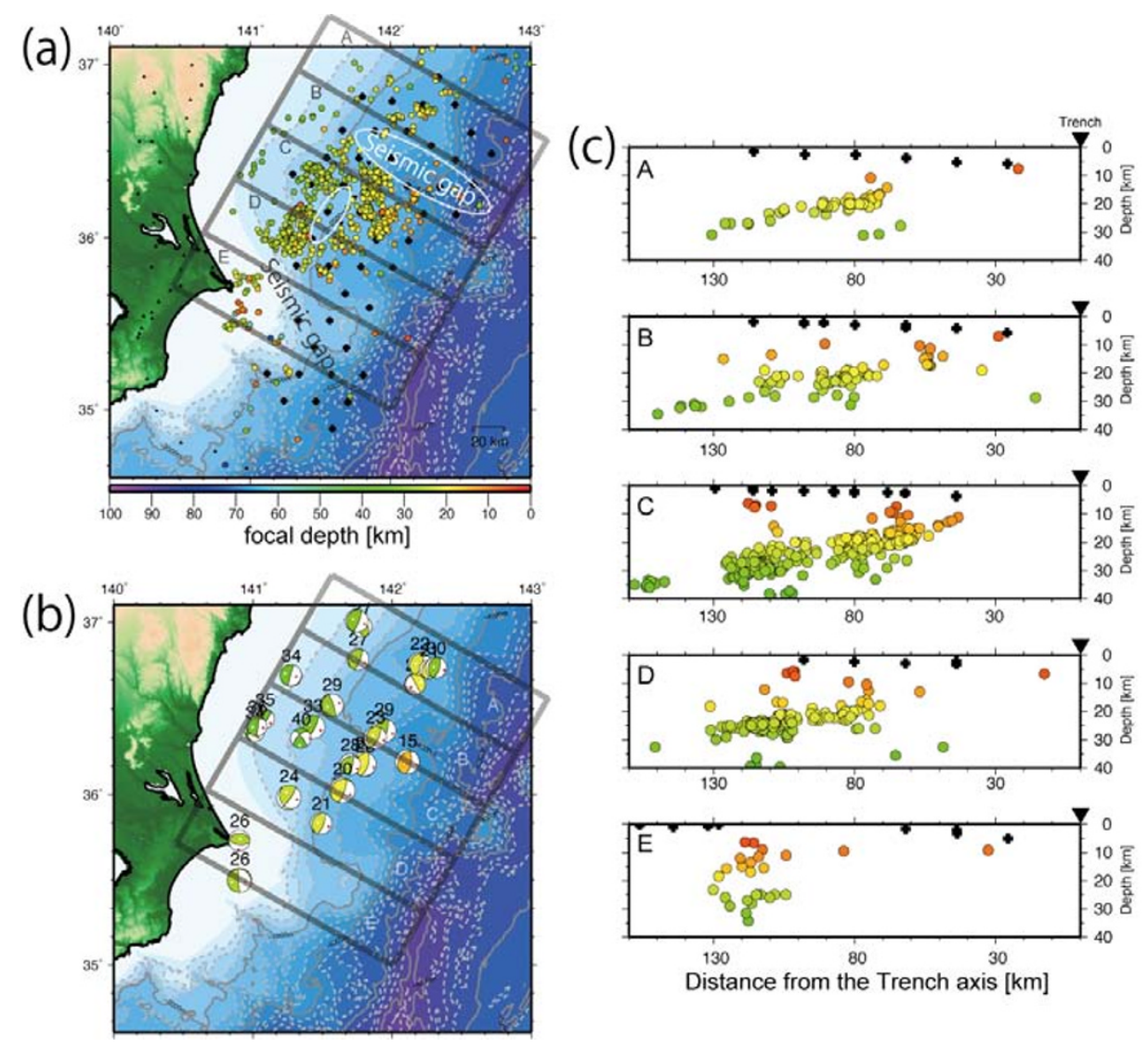

Fig. 2. (a) Hypocenter distribution from May 19 to October 26, 2008. 851 foci are plotted as circles. Color corresponds to focal depth. Other marks are same as in Fig. 1. The five rectangles depict the areas in (c). There are some seismic gap, such as in region B (white oval with white letters), between regions $\mathrm{C}$ and $\mathrm{D}$ (white oval) and between regions D and $\mathrm{E}$ (black letters). Moreover, few earthquakes are located near the trench. (b) Mechanism solution by NIED with focal depth deduced from this study. Thrust type earthquakes are prominent in regions A-D, although no thrust type in region E. (c) Vertical cross-sections of the hypocenters in the forearc region. Most earthquakes distribute the subducting direction of PAC in regions A-D. In contrast, the trend is unclear in region $\mathrm{E}$.

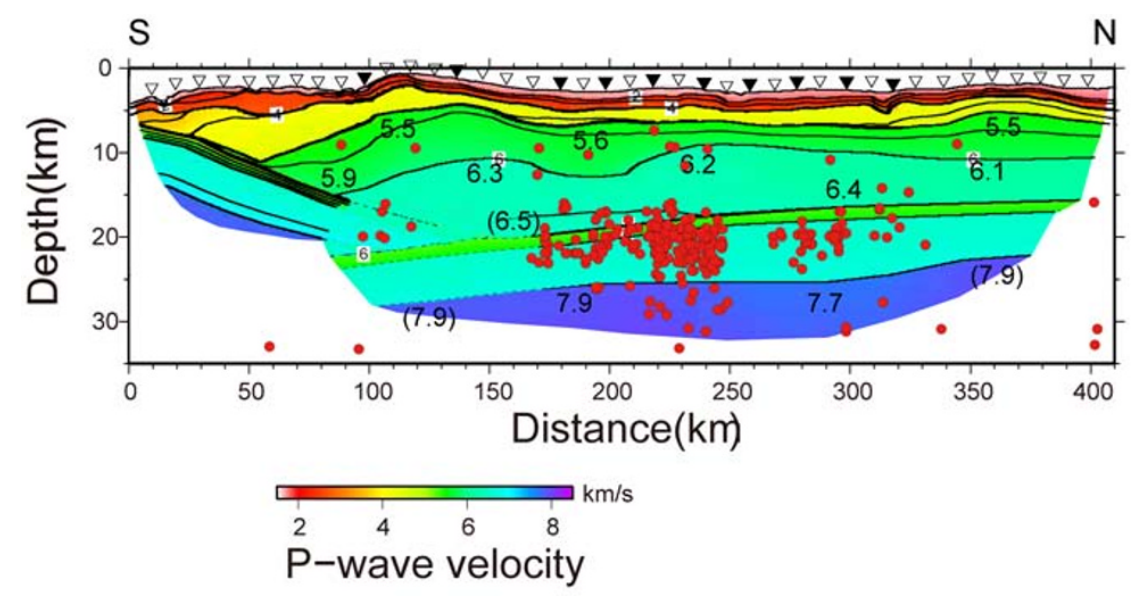

Fig. 3. Depth section through a $P$-wave velocity model on the profile shown in Fig. 1(b) with superimposed hypocenters (red circles) distributed within $15 \mathrm{~km}$ in the horizontal direction. Open inverted triangles indicate temporal OBSs for the velocity structural analysis only and solid inverted triangles are our OBSs for both the velocity analysis and hypocenter location. The edge of the PHS seems to be located on between $130 \mathrm{~km}$ and $170 \mathrm{~km}$ in the horizontal axis.

tion with the aftershocks determined by JMA after the $M_{\mathrm{j}} 9.0$ earthquakes (Fig. 4). We must pay attention to the uncertainty of the JMA location particularly in depth, related to the sparse station coverage in the study area. In fact, discrepancies in the focal depths tend to be larger as the horizontal distances from the coast increase. In contrast, the epicenters are relatively more reliable than the focal depths in principle and Fig. 4 shows that there is a remarkably common seismic gap in both 2008 and 2011.

Figure 5 shows time sequences in hypocenter distribution. During the 29 minutes from the origin time of the 2011 Tohoku earthquake, large aftershocks were distributed 


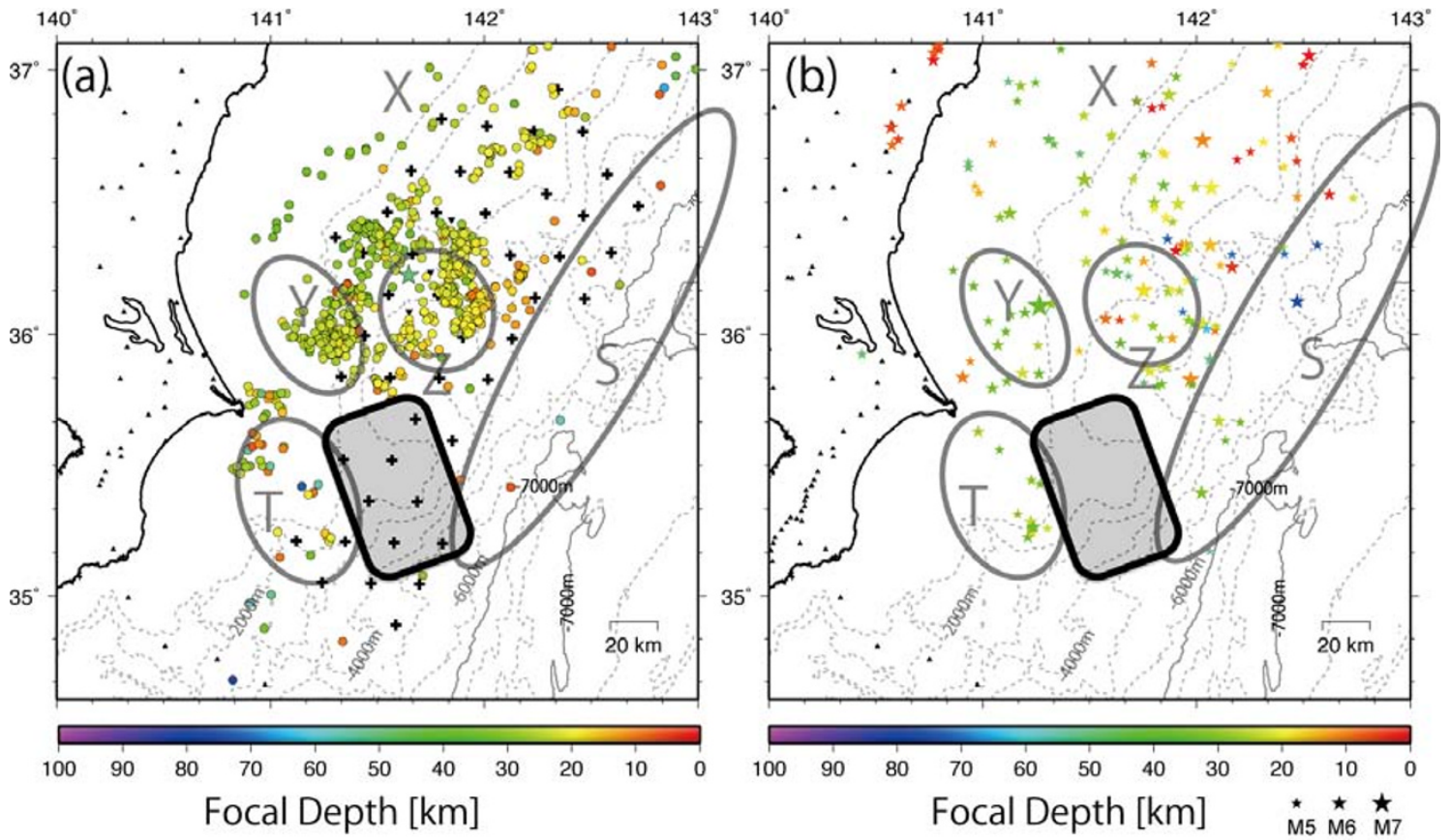

Fig. 4. (a) Hypocenter distribution from May 19 to October 26, 2008 with the 2008 earthquake on May 8, 2008 (Japan Standard Time). Circles denote hypocenters in this study and the star in region $\mathrm{Z}$ shows the 2008 earthquake. Color corresponds to focal depth. The rounded rectangle is a remarkable seismic gap. Broken and solid lines denote contour intervals of $1 \mathrm{~km}$ and $7 \mathrm{~km}$ water depth, respectively. (b) Aftershock distribution (March 11-31, $2011, M_{\mathrm{j}}>5.0$ ) by JMA. Stars show the aftershocks. Color and size of the stars correspond to focal depth and magnitude, respectively. The largest green star in grey circle $\mathrm{Y}$ indicates the $M_{\mathrm{j}} 7.7$ earthquake. It is located in one of the high seismicity regions in (a). The rounded triangle is the remarkable seismic gap. Broken and solid lines denote contour intervals of $1 \mathrm{~km}$ and $7 \mathrm{~km}$ water depth, respectively. X, Y, Z, S and T correspond to those in Fig. 5.
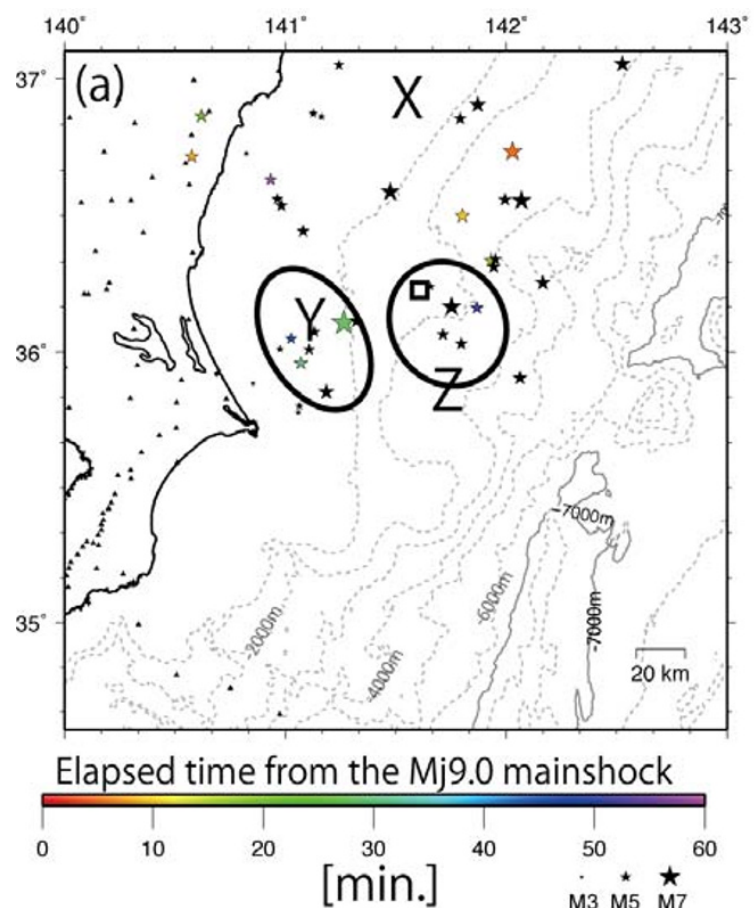

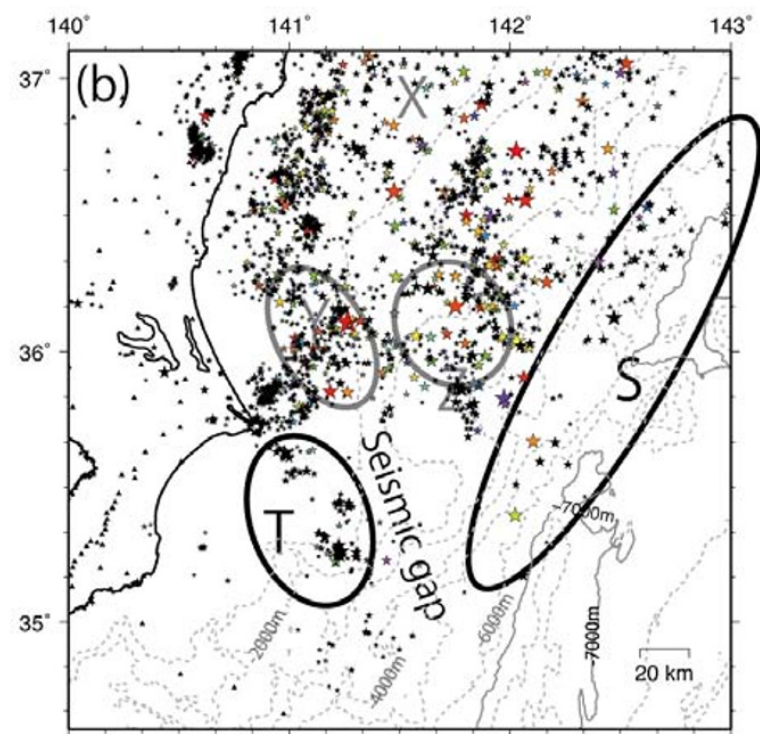

Elapsed time from the Mj9.0 mainshock

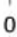

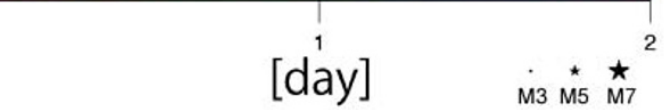

Fig. 5. (a) Time sequences of the aftershocks $\left(M_{\mathrm{j}}>3.0\right)$, which occurred within 4 hours after the mainshock. Color indicates the elapsed time from the mainshock and black means that the events occurred from 1 hour to 4 hours after the mainshock. Aftershocks had only occurred in region X before the $M_{\mathrm{j}} 7.7$ earthquakes occurred in region Y. At that time, there were no large earthquakes in region Z, where the 2008 earthquake $\left(M_{\mathrm{j}} 7.0\right)$ occurred. The square shows the $M_{\mathrm{j}} 7.0$ foci for reference. (b) Time sequences of the aftershocks $\left(M_{\mathrm{j}}>3.0\right)$, which occurred on March, 2011. Color indicates the elapsed time from the mainshock, and black means 2 days or more after the mainshock. Following activities in regions $\mathrm{X}$, Y and $\mathrm{Z}$, remarkable aftershocks occurred in region $\mathrm{S}$ just close to the Japan Trench and in region T where PHS exists. 
only in the north of $36^{\circ} 20^{\prime} \mathrm{N}$, region $\mathrm{X}$. About 30 minutes after the main shock, a $M_{\mathrm{j}} 7.7$ event hit in region Y. After that, remarkable seismic activity in region $\mathrm{Z}$, where the 2008 Ibaraki-oki earthquake $\left(M_{\mathrm{j}} 7.0\right.$, May 8,2008$)$ had occurred, started within 1 hour. Following these, aftershocks spread close to the trench (region S) and the southward (region T), where PHS exists within 2 days. The edge of the PHS is located at the boundary zone between regions $\mathrm{Y}, \mathrm{Z}$ and $S$ and region $T$ and it corresponds to the seismic gap in Fig. 4 and between regions D and E in Fig. 3. From geometrical and seismological viewpoints, PHS seems to affect the condition.

Mochizuki et al. (2008) proposed that subducted seamounts caused low friction in the plate boundary and created seismically quiet areas. One of these corresponds to the other seismic gap in region B in Fig. 3 and it is the boundary zone between region $\mathrm{X}$ and $\mathrm{Z}$. Moreover, focal depths by JMA near the Japan Trench in regions B and C in Fig. 2 have remarkable variations. The fact that our results do not show the large variation in depth in the region implies that there is great heterogeneous velocity structure.

The other boundary between region $S$ near the trench and regions $\mathrm{X}$ and $\mathrm{Z}$ seems to match the so-called up-dip limit for the seismogenic zone (e.g., Tsuru et al., 2000). Regions near trenches such as region $\mathrm{S}$, are known as strong tsunami generation areas, and background seismicity is relatively low, although the aftershocks were located in them and the notion of up-dip limit should be reconsidered.

These characteristics in the boundary zones strongly suggest that structural heterogeneities are key to understanding basic information such as where, when and how earthquakes occur. We anticipate that there is some heterogeneity on the plate boundary between regions $\mathrm{Y}$ and $\mathrm{Z}$.

\section{Conclusions}

We conducted ocean bottom seismographic observations in 2008 and estimated 851 hypocenter locations around the south part of the 2011 Tohoku earthquake. We found several seismic gaps and the most remarkable one is positioned near the edge of the PHS. The aftershocks are segmented spatially and there are some seismic gaps among segmentations. We infer that the seismic gaps have strong heterogeneity resulting from strong deformations. Various subduction processes such as intervened PHS between NA and PAC, seamount chains and variations in physical properties have the ability to cause the deformations.

Acknowledgments. The authors are grateful to Messrs T. Yagi, S. Hashimoto, N. Takeda, S. Suzuki, K. Suzuki, R. Amamiya and Drs. T. Shinbo, Y. Yamamoto, R. Azuma, and R. Miura for helping OBS experiments. Anonymous reviewers gave us very helpful comments. We are grateful to NIED and JMA for allowing us to use the waveform data collected at on-line seismic stations and from earthquake catalogs. This research was partially supported by the Ministry of Education, Culture, Sports, Science and Tech- nology (MEXT) of Japan, and by the cooperative research program of the Earthquake Research Institute, University of Tokyo.

\section{References}

Fukuyama, E., S. Ishida, D. S. Dreger, and H. Kawai, Automated seismic moment tensor determination by using on-line broadband seismic waveforms, Zisin, 51, 149-156, 1998.

Hino, R., Y. Yamamoto, A. Kuwano, M. Nishino, T. Kanazawa, T. Yamada, K. Nakahigashi, K. Mochizuki, M. Shinohara, K. Minato, G. Aoki, N. Okawara, M. Tanaka, M. Abe, E. Araki, S. Kodaira, G. Fujie, and Y. Kaneda, Hypocenter distribution of the main- and aftershocks of the 2005 Off Miyagi Prefecture Earthquake located by ocean bottom seismographic data, Earth Planets Space, 58, 1543-1548, 2006.

Kanazawa, T., T. Yamada, M. Shinohara, S. Sakai, and M. Mochizuki, Robot sea-floor seismometer for a long-term observation, Chikyu, extra edition, 51, 176-180, 2005.

Lomax, A., A. Michelini, and A. Curtis, Earthquake location, direct, global-search methods, in Complexity In Encyclopedia of Complexity and System Science, Part 5, pp. 2449-2473, doi:10.1007/978-0-38730440-3, Springer, New York, 2009.

Miura, S., S. Kodaira, A. Nakanishi, T. Tsuru, N. Takahashi, N. Hirata, and Y. Kaneda, Structural characteristics controlling the seismicity of southern Japan Trench fore-arc region revealed by ocean bottom seismographic data, Tectonophysics, 363, 79-102, 2003.

Mochizuki, K., T. Yamada, M. Shinohara, Y. Yamanaka, and T. Kanazawa, Weak interplate coupling by seamounts and repeating $\mathrm{M} \sim 7$ earthquakes, Science, 321, 1194-1197, 2008.

Shinohara, M., T. Kanazawa, T. Yamada, K. Nakahigashi, S. Sakai, R. Hino, Y. Murai, A. Yamazaki, K. Obana, Y. Ito, K. Iwakiri, R. Miura, Y. Machida, K. Mochizuki, K. Uehira, M. Tahara, A. Kuwano, S. Amamiya, S. Kodaira, T. Takanami, Y. Kaneda, and T. Iwasaki, Precise aftershock distribution of the 2007 Chuetsu-oki Earthquake obtained by using an ocean bottom seismometer network, Earth Planets Space, 60, 1121-1126, 2008.

Shinohara, M., T. Yamada, and T. Kanazawa, Development of ocean bottom accelerometer for observation of strong motion on sea floor, J. Jpn. Soc. Mar. Surv. Tech., 21, 15-24, 2009.

Shinohara, M., T. Yamada, K. Nakahigashi, S. Sakai, K. Mochizuki, K. Uehira, Y. Ito, R. Azuma, Y. Kaiho, T. No, H. Shiobara, R. Hino, Y. Murai, H. Yakiwara, T. Sato, Y. Machida, T. Shinbo, T. Isse, H. Miyamachi, K. Obana, N. Takahashi, S. Kodaira, Y. Kaneda, K. Hirata, S. Yoshikawa, K. Obara, T. Iwasaki, and N. Hirata, Aftershock observation of the 2011 off the Pacific coast of Tohoku Earthquake by using ocean bottom seismometer network, Earth Planets Space, 63, this issue, 835-840, 2011.

Tsuru, T., J. Park, N. Takahashi, S. Kodaira, Y. Kido, Y. Kaneda, and Y. Kono, Tectonic features of the Japan Trench convergent margin off Sanriku, northeastern Japan, revealed by multichannel seismic reflection data, J. Geophys. Res., 105(B7), 16403-16413, 2000.

Uchida, N., T. Matsuzawa, J. Nakajima, and A. Hasegawa, Subduction of a wedge-shaped Philippine Sea plate beneath Kanto, central Japan, estimated from converted waves and small repeating earthquakes, $J$. Geophys. Res., 115, B07309, doi:10.1029/2009JB006962, 2010.

Urabe, T. and S. Tsukada, A workstation-assisted processing system for waveform data from microearthquake networks, Abstracts of Spring Meeting of Seismological Society of Japan, p70, 1991.

Yamada, T., M. Shinohara, T. Kanazawa, N. Hirata, Y. Kaneda, T. Takanami, H. Mikada, K. Suyehiro, S. Sakai, T. Watanabe, K. Uehira, Y. Murai, N. Takahashi, M. Nishino, K. Mochizuki, T. Sato, E. Araki, R. Hino, K. Uhira, H. Shiobara, and H. Shimizu, Aftershock distribution of the 2003 Tokachi-oki Earthquake derived from high-dense network of ocean bottom seismographs, Zisin, 57, 281-290, 2005.

T. Yamada (e-mail: yamada@eri.u-tokyo.ac.jp), K. Nakahigashi, A. Kuwano, K. Mochizuki, S. Sakai, M. Shinohara, R. Hino, Y. Murai, T. Takanami, and T. Kanazawa 